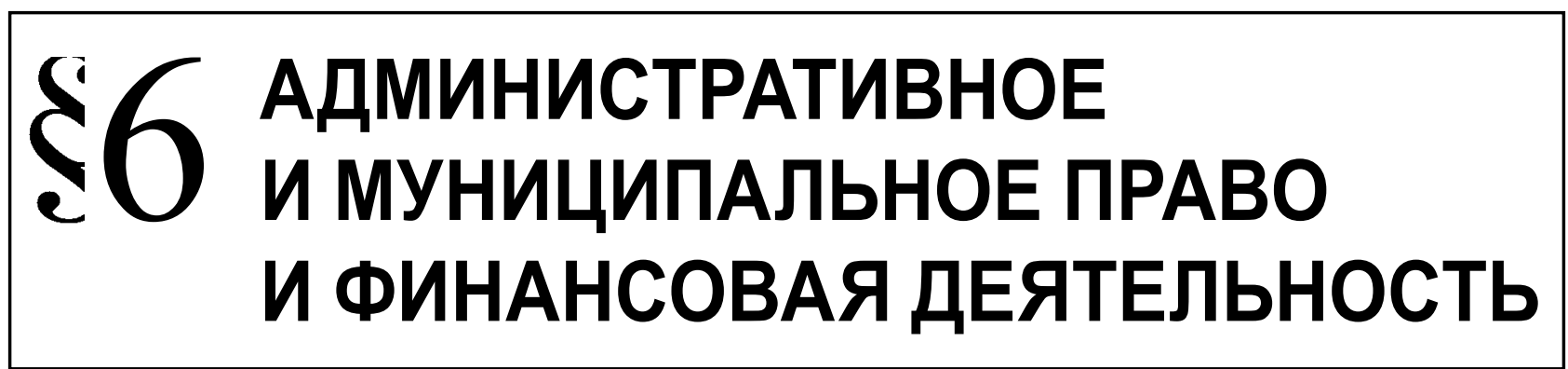

Шагиева Р.В.

\title{
ТЕОРЕТИЧЕСКИЕ ОСНОВЫ ИССЛЕДОВАНИЯ ФИНАНСОВОЙ ДЕЯТЕЛЬНОСТИ В НАУКЕ ФИНАНСОВОГО ПРАВА
}

Аннотация: Данная статья посвящена теории финансовой деятельности, в ней рассматривается финансовая деятельность, анализируется ее социальная природа. Автор обосновывает, что она представляет собой правовое, а не экономическое явление, в связи с чем особое внимание уделено правовым формам ее осуществления в современном обществе. Даже беглый анализ литературы, посвященной данной проблеме, показывает, что большинство определений понятия финансовой деятельности государства и финансовой деятельности муниципальных образований не содержат принципиальных различий. Финансовая деятельность государства - это осуществление им функций по планомерному образованию (формированию), распределению и использованию денежных фондов (финансовых ресурсов) в целях реализации задач социально-экономического развития, поддержанию обороноспособности и безопасности страны, а также обеспечения финансовыми ресурсами деятельности государственных органов. Финансовая деятельность государства в науке финансового права рассматривается как особый вид государственной деятельности потому, что этот вид деятельности осуществляют органы государства всех трех ветвей - законодательной, исполнительной и судебной - в пределах имеющейся у них компетенции. Финансовая деятельность государства в первую очередь направлена на создание, распределение (перераспределение) и использование фондов денежных средств, находящихся на праве собственности у государства (федерального бюджета, бюджетов субъектов Российской Федерации, государственных внебюджетных фондов, фондов государственных унитарных предприятий, в том числе казенных предприятий, и других организаций, функционирующих на праве государственной собственности). Однако, по нашему мнению, финансовая деятельность государства, его органов охватывает своим воздействием также и процесс создания, распределения и в определенной части использования фондов денежных средств хозяйствующими субъектами, действующими на праве частной собственности. Финансовую деятельность государства можно определить как особый вид государственной деятельности, направленной на совершение организационных и иных действий органов государства, как правило, в правовой форме, в процессе распределения внутреннего валового продукта и части национального дохода общества путем образования, распределения (перераспределения) и использования различных фондов денежных средств, как централизованных, так и децентрализованных, необходимых для обеспечения финансовыми ресурсами функционирования органов государства всех трех ветвей власти, осуществления мероприятий по внутренней безопасности и обороне страны, для выполнения национальных программ социально-экономического и культурного развития и удовлетворения иных потребителей общества. Органы местного самоуправления также осуществляют финансовую деятельность по созданию, распределению и использованию фондов денежных средств, необходимых для финансового обеспечения решения вопросов местного значения.

Ключевые слова: финансовая деятельность государства, деятельность муниципальных образований, финансы, финансовые ресурсы, денежные средства, денежные фонды, финансовое право, муниципальное образование, национальная безопасность, экономика. 
B современном обществе государство не может выполнять свои задачи и функции по управлению обществом и обеспечению его жизнедеятельности, не располагая необходимыми финансовыми (денежными) ресурсами. Возникновение и осуществление финансовой деятельности обусловлены необходимостью создания различных фондов денежных средств для финансового обеспечения соответствующих потребностей государства, муниципальных образований и хозяйствующих субъектов. Фонды финансовых (денежных) ресурсов, необходимые государству и муниципальным образованиям для осуществления своих задач и функций, стихийно не создаются. Они образуются в результате планомерных действий органов государства, муниципальных образований, направленных на создание, распределение и использование указанных фондов. Действия органов государства и муниципальных образований по созданию, распределению и использованию фондов денежных средств в своей совокупности составляют содержание деятельности государства и муниципальных образований в сфере финансов, при распределении и перераспределении совокупного общественного продукта, в том числе и части национального дохода. Данная форма человеческого воздействия на внешний мир, на общественные отношения в области финансов и получила в науке финансового права название "финансовая деятельность государства”, “финансовая деятельность муниципальных образований”. Неслучайно Е.A. Ровинский в свое время отмечал, что через финансовую деятельность государства отражается (осуществляется) взаимосвязь государства и экономики общества ${ }^{1}$.

Однако в действующем законодательстве не содержится легального определения ни понятия «финансовая деятельность государства», ни понятия «финансовая деятельность муниципальных образований». Содержание данных категорий «финансовая деятельность государства и муниципальных образований» раскрывается в науке финансового права.

Даже беглый анализ литературы, посвященной данной проблеме, показывает, что большинство определений понятия финансовой деятельности государства и финансовой деятельности муниципальных образований не содержат принципиальных различий. Так, например, Н.И. Хи-

\footnotetext{
1 См.: Ровинский Е.А. Основные вопросы советского финансового права. М.: Госюриздат, 1960. С. 6, 7.
}

мичева отмечает, что финансовая деятельность государства - это осуществление им функций по планомерному образованию (формированию), распределению и использованию денежных фондов (финансовых ресурсов) в целях реализации задач социально-экономического развития, поддержанию обороноспособности и безопасности страны, а также обеспечения финансовыми ресурсами деятельности государственных органов ${ }^{2}$.

По мнению О.Н. Горбуновой, финансовая деятельность государства - деятельность государства по образованию, перераспределению и использованию централизованных и децентрализованных фондов денежных средств, обеспечивающих бесперебойное функционирование государства на каждом данном этапе общественного развития ${ }^{3}$.

М.В. Карасева пишет: «Финансовая деятельность государства и муниципальных образований представляет собой процесс планомерного образования, распределения и использования государством и муниципальными образованиями финансовых ресурсов через свои денежные фонды для выполнения поставленных задач» 4 .

А.Э. Лоскутов правильно отмечает, что финансовая деятельность осуществляется посредством использования финансовой системы государства ${ }^{5}$.

Подробный анализ существующих в литературе точек зрения ученых по вопросу финансовой деятельности государства провел А.И. Худяков, который обоснованно отмечает, что понятие финансовой деятельности государства было сформулировано в рамках юридической науки. Однако А.И. Худяков категорически возражает против взглядов тех ученых, которые полагают, что объектом финансовой деятельности государства могут выступать и негосударственные денежные фонды.

«Если же посмотреть учебную литературу по финансовому праву, - пишет А.И. Худяков, - то

\footnotetext{
2 Финансовое право: Учебник / Отв. ред. Н.И. Химичева. 3-е изд., перераб. и доп. М.: Юристъ, 2003. С. 85.

3 Финансовое право: Учебник / Под ред. О.Н. Горбуновой. 2-е изд., перераб. и доп. М.: Юристъ, 2000. С. 16.

4 Карасева М.В. Финансовое право. Общая часть: Учебник. М.: Юристъ, 1999. С. 14. Аналогично ее определяют и другие авторы: См.: Крохина Ю.А. Финансовое право России: Учебник. 3-е изд., перераб. и доп. М.: НОРМА, 2008. С. 36.

См.: Лоскутов А.Э. Распределение налоговых доходов между государственными и местными бюджетами: сравнительно-правовое исследование. Автореферат дис. ... канд. юрид. наук. Саратов, 2006. С. 3.
} 
нетрудно заметить, что в ней в качестве объекта финансово-правового регулирования рассматриваются все виды денежных фондов, как государственные, так и негосударственные. Что же касается практики правового регулирования, то она также стоит на этой позиции. Фактически это означает, что денежные фонды негосударственных организаций, опосредуемые категорией «частные финансы», выступают объектом финансового права наравне с государственными денежными фондами, которые выражают государственные финансы». И далее А.И. Худяков отмечает, что «...сфера финансовой деятельности государства должна быть ограничена государственными денежными фондами» ${ }^{6}$.

Включение негосударственных денежных фондов в объекты финансовой деятельности государства не означает, по нашему мнению, установления единого правового режима для государственных и негосударственных денежных фондов. Но государство и муниципальные образования, осуществляя финансовую деятельность, определяют, предусматривают «правила игры» в сфере финансов как для субъектов, действующих на праве государственной или муниципальной собственности, так и для субъектов, функционирующих на праве частной собственности, при этом, подчеркивая, что более «жесткие» правила устанавливаются для первой группы субъектов ${ }^{7}$.

А.И. Худяков определяет финансовую деятельность государства следующим образом: «Это деятельность государства, выступающего в целом или в лице уполномоченных на то органов, по созданию денежной инфраструктуры страны и обеспечению ее надлежащего функционирования, а также по формированию, распределению и организации использования государственных денежных фондов» ${ }^{8}$.

Особая позиция данного ученого выражается не только в отрицании возможности необоснованного, по его мнению, расширения сферы финансовой деятельности государства за счет включения в нее объектов негосударственных фондов денежных средств, но и в том, что А.И. Худяков вводит новый элемент в понятие финансовой деятельности государства - «создание денежной

\footnotetext{
6 Худяков А.И. Финансовое право Республики Казахстан. Общая часть. 2001. С. 16, 17.

7 См.: Соколова Э.Д. Правовые основы финансовой системы России / Отв. ред. Е.Ю. Грачева. М.: ИД «Юриспруденция», 2006. С. 29.

8 Худяков А.И. Назв. соч. С. 19.
}

инфраструктуры страны», а также несколько изменяет «триаду» (образование, распределение, использование), применяемую авторами при характеристике финансовой деятельности государства, отражая организационный признак в использовании государственных денежных фондов. По нашему мнению, с одной стороны, неудачно применено слово «инфраструктура» при характеристике финансовой деятельности государства, обусловленной объективными потребностями развития общества, а с другой - организационный признак присущ всей финансовой деятельности государства, а не только использованию государственных денежных фондов.

Кроме того, поскольку совокупный общественный продукт общества и часть его - национальный доход, распределяется и перераспределяется в денежной форме, поэтому возникновение денежной системы так же обусловлено объективной необходимостью, как и сама финансовая деятельность государства и муниципальных образований.

А.И. Худяков также предлагает «несколько сузить понятие финансовой деятельности государства за счет исключения из ее состава действий, связанных с использованием денежных средств...» ${ }^{9}$.

Нам представляется, что слово «использование», широко применяемое в науке финансового права для характеристики финансовой деятельности государства, вполне отвечает сущности отношений, возникающих при ее осуществлении, и не выражает собой отношения обмена, т.е. товарно-денежные отношения по схеме Т-Д или Д-Т. «Использовать» означает воспользоваться (пользоваться) чем-нибудь, употребить с пользой ${ }^{10}$. Не в этом ли заключается, например, стадия исполнения бюджета, когда в соответствии с законом денежные средства направляются главным распорядителям бюджетных средств, распорядителям и получателям для их дальнейшего употребления с пользой, т.е. в соответствии с финансовым планом. Слово «использовать», по нашему мнению, более объемное по содержанию, чем слово «расходовать». Расходовать означает тратить, употреблять на что-нибудь ${ }^{11}$. В основе слова «использовать»

\footnotetext{
9 Худяков А.И. Основы теории финансового права. М., 1995. С. 33

10 См.: Ожегов С.И., Шведова Н.Ю. Толковый словарь русского языка. М.: Азъ, 1994. С. 254.

11 Там же. С. 668.
} 
лежит правомочие, предоставленное кем-то для осуществления определенного им результативного действия. Слово «расходовать» - узкое по содержанию слово, предполагающее совершение конкретного действия. Вот почему, на наш взгляд, вполне уместно употреблять слово «использование» при характеристике финансовой деятельности, а слово «расходовать» применимо для гражданского оборота.

Таким образом, финансовую деятельность государства можно определить как особый вид государственной деятельности, направленной на совершение организационных и иных действий органов государства, как правило, в правовой форме, в процессе распределения внутреннего валового продукта и части национального дохода общества путем образования, распределения (перераспределения) и использования различных фондов денежных средств, как централизованных, так и децентрализованных, необходимых для обеспечения финансовыми ресурсами функционирования органов государства всех трех ветвей власти, осуществления мероприятий по внутренней безопасности и обороне страны, для выполнения национальных программ социально-экономического и культурного развития и удовлетворения иных потребителей общества. Органы местного самоуправления также осуществляют финансовую деятельность по созданию, распределению и использованию фондов денежных средств, необходимых для финансового обеспечения решения вопросов местного значения.

Финансовая деятельность государства в науке финансового права рассматривается как особый вид государственной деятельности потому, что этот вид деятельности осуществляют органы государства всех трех ветвей - законодательной, исполнительной и судебной - в пределах имеющейся у них компетенции. Финансовая деятельность государства в первую очередь направлена на создание, распределение (перераспределение) и использование фондов денежных средств, находящихся на праве собственности у государства (федерального бюджета, бюджетов субъектов Российской Федерации, государственных внебюджетных фондов, фондов государственных унитарных предприятий, в том числе казенных предприятий, и других организаций, функционирующих на праве государственной собственности).

Однако, по нашему мнению, финансовая деятельность государства, его органов охватывает своим воздействием также и процесс создания, распределения и в определенной части использования фондов денежных средств хозяйствующими субъектами, действующими на праве частной собственности. Публичный характер данного вида государственной деятельности в отношении хозяйствующих субъектов, функционирующих на праве частной собственности, проявляется в первую очередь в установлении определенных условий участия всех хозяйствующих субъектов вне зависимости от формы собственности в создании централизованных государственных фондов денежных средств. Это положение, в свою очередь, обусловливает необходимость проведения государственного финансового контроля деятельности хозяйствующих субъектов по созданию, распределению и использованию ими соответствующих фондов денежных средств.

Финансовая деятельность государства и муниципальных образований осуществляется в различных формах, как в правовых, так и в неправовых. Правовые формы выражаются в принятии различных нормативных правовых актов органами государства и органами местного самоуправления в пределах своей компетенции, которые содержат общее правило поведения, а также издание индивидуальных финансово-правовых актов и их практическую реализацию. Большое значение имеет принятие и выполнение финансово-плановых актов (федерального бюджета, бюджетов субъектов Федерации, местных бюджетов, бюджетов государственных внебюджетных фондов, бюджетных смет бюджетных учреждений, бизнес-план и т.д.). Неправовые формы финансовой деятельности, как отмечается в литературе, - это «различные практические действия, юридического значения не имеющие, но способствующие принятию таких актов или применению правовых норм. Это инструктирование, проведение совещаний, заседаний, разъяснение финансового законодательства и т.д. 12. Как в правовой, так и в неправовой форме могут осуществляться организационные действия по созданию, распределению (перераспределению) и использованию фондов денежных средств.

На существование данного различия обращали внимание еще государствоведы в начале XX века. Так, в частности, теоретики французского административного права различали две формы государственной деятельности: государство как при-

12 Химичева Н.И., Покачалова Е.В. Финансовое право / Отв. ред. докт. юрид. наук, проф. Н.И. Химичева. М.: Норма, 2005. C. 104. 
нудительная повелевающая сила (в данном случае деятельность государства выражается в обязательных предписаниях для подданных власти); государство как представитель общественных интересов (здесь его деятельность выражается не в предписаниях подданным, а в организации и осуществлении государственных мероприятий) ${ }^{13}$.

В настоящее время эту проблему чаще всего рассматривают в связи с исследованием правовых форм деятельности государства (или правовых способов государственного воздействия на общественные отношения). Обычно правовые формы деятельности государства сравниваются с фактической деятельностью государства, не влекущей правовых последствий (организационномассовая, культурно- и политико-воспитательная, учетно-статистическая и др.). Действительно, хотя правотворчество, правоприменение и другие виды юридической деятельности связаны с фактическим разрешением специфических, относительно самостоятельных и разноплановых задач, имеющих общегосударственное значение, тем не менее, каждая из них регламентируется различными по своей специфике блоками материальных и процедурно-процессуальных норм и сопровождается (завершается) различными правовыми последствиями. Вне этих видов собственно юридической деятельности любая иная деятельность государства, заканчивающая фактическим проведением в жизнь текущих и других законов во всех сферах общественной жизни общества, не может претендовать на чисто юридическую форму, хотя она в решающих чертах и основывается на действующем праве. Такая организационная деятельность, которая не требует полного и строгого юридического оформления, не связана с совершением юридически обязательных актов. Обусловлено это тем, что государство не в состоянии учесть во всех деталях постоянные изменения в динамично развивающемся обществе, закрепить их в системе права, да и не все они требуют скрупулезной юридической регламентации. Если признать, что государство функционирует только в рамках позитивного права, то придется допустить, что отсутствие юридического установления в какой-либо сфере жизни неминуемо повлечет бездействие государства в тех случаях, когда возникшая ситуация не вписывается в ранее изданный правовой акт. «У государственного органа, - замечал еще И.

13 См.: Леруа Максим. Эволюция государственной власти (синдикаты чиновников) / Пер. с фр. СПб., 1907. С. 47.
Сабо, - всегда остается сфера «свободной» деятельности, определяемой принципом целесообразности, который иногда закрепляется в правовой форме. Конечно, такая «свободная» деятельность не свободна в том смысле, что детерминирована как неправовыми факторами, так и общей правовой регламентацией порядка деятельности государственных органов» ${ }^{14}$.

Сказанное не означает, что организационная деятельность никак не регулируется правом. Она осуществляется в рамках действующего законодательства и в пределах компетенции того или иного органа. Однако (и это принципиально) правом здесь регламентируется лишь общая процедура совершения действий. Организационные действия не нуждаются в издании специальных юридических актов и проводятся в порядке текущей, прежде всего управленческой, деятельности. В то же время как предпосылки, так и результат выполнения организационных действий могут фиксироваться и юридически. В литературе называют следующие направления организационной (фактической) деятельности государства: культурно-массовая, технически-исполнительная, организационно-экономическая деятельность и вооруженная защита страны. Помимо собственно организационной деятельности к неправовым формам относят осуществление материально-технических операций, таких, как: подготовка материалов для издания юридических актов, составления справок, отчетов, ведение делопроизводства и т.д.

Осуществление организационных действий это повседневные и разнообразные проявления управленческой деятельности, лишенные юридической оболочки. Они широко используются для обеспечения четкой и эффективной работы органов государственной власти. Организационные действия могут быть направлены как внутрь аппарата государства, так и вовне его - в отношении негосударственных формирований и граждан. ${ }^{15}$

В науке административного права к таковым относят также инспектирование, инструктирование, разъяснение содержания и целей законов, проведение совещаний, рассылку информационных материалов, оказание практической помощи на месте и т.п. Все эти действия в силу их разнообразия и

14 Сабо И. Основы теории права / Пер. с венг. М., 1974. C. 118 .

15 См.: Грудцына Л.Ю. Гражданское общество и частное право // Международный академический журнал Российской академии естественных наук. 2013. № 4. С. 69-79. 
неповторимости не оформляются позитивным правом. Однако реализация их находится в непосредственной связи с основными видами собственно юридической деятельности. Неслучайно полагают, что это различие носит чисто условный характер ${ }^{16}$.

Например, обеспечение правильного сочетания единоначалия и коллегиальности, подготовка и проведение заседаний и совещаний, распределение функций и обязанностей между структурными подразделениями государственного органа, изучение, обобщение и распространение положительного опыта и т.п. Все возрастающую роль играют изучение и учет общественного мнения в работе государственного аппарата. Применительно к негосударственным формированиям и гражданам можно говорить о различных формах привлечения общественных и самодеятельных организаций и граждан к работе государственных органов, об организационно-массовой работе последних и т.п. ${ }^{17}$.

Думается, что исследовательская практика разграничения собственно юридической и организационной (фактической) деятельности государства является в целом полезной, в том числе и для понимания природы финансовой деятельности. Тем не менее, используемые термины «правовые формы» и «неправовые (фактические, организационные) формы» деятельности государства всегда представлялись не совсем точными и требовали дополнительных разъяснений. Скажем, к примеру, о том, что правотворчество может осуществляться не только государственными органами, но и народом или органами местного самоуправления, или о том, что организационные мероприятия во многом влияют на правовую реальность и, в конечном счете, юридически опосредованы и т.д.

Разумеется, никаких непреодолимых препятствий между правовыми и организационными (фактическими) формами финансовой деятельности нет и быть не может. В юридической литературе категорически утверждалось, что так называемая фактическая деятельность государства протекает при строжайшем соблюдении законов ${ }^{18}$. Всякая деятельность государства протекает в рамках правовых предписаний, и вследствие этого нет необходимости обосновывать неправовую форму государственной деятельности.

В аспекте приведенных рассуждений приходится констатировать, что финансовая деятельность государства и финансовая деятельность муниципальных образований вряд ли относится к «базовым категориям экономической науки» (финансы, финансовая система, финансовая деятельность) ${ }^{19}$, ее вполне обоснованно считают правовой категорией ${ }^{20}$.

\section{Библиография:}

1. Актуальные проблемы теории и практики государственной деятельности / Отв. ред. проф. И.А. Галаган. Воронеж, 1990, С. 45.

2. Веремеенко И.И. К вопросу о предмете финансового права. Актуальные вопросы административного и финансового права: Сборник научных трудов. Вып. 2. М.: МГИМО(У) МИД России, 2004. С. 12.

3. Витченко А.М. Теоретические проблемы исследования государственной власти. Саратов, 1982. С. 186.

4. Грудцына Л.Ю. Гражданское общество и частное право // Международный академический журнал Российской академии естественных наук. 2013. № 4. С. 69-79.

5. Карасева М.В. Финансовое право. Общая часть: Учебник. М.: Юристъ, 1999. С. 14.

6. Карасева М.В., Крохина Ю.А. Финансовое право / Под ред. докт. юрид. наук, проф. М.В. Карасевой. М.: Издательство «Норма» (Издательская группа Норма-Инфра), 2001. С. 9.

\footnotetext{
16 См.: Актуальные проблемы теории и практики государственной деятельности / Отв. ред. проф. И.А. Галаган. Воронеж, 1990, С. 45.

17 См. об этом: Теория права и государства: Учебник / Под ред. проф. В.В. Лазарева. М., 1996. С. 342-343.
} 
7. Крохина Ю.А. Финансовое право России: Учебник. 3-е изд., перераб. и доп. М.: НОРМА, 2008. С. 36.

8. Леруа Максим. Эволюция государственной власти (синдикаты чиновников) / Пер. с фр. СПб., 1907. С. 47.

9. Лоскутов А.Э. Распределение налоговых доходов между государственными и местными бюджетами: сравнительно-правовое исследование. Автореферат дис. ... канд. юрид. наук. Саратов, 2006. С. 3.

10. Ожегов С.И., Шведова Н.Ю. Толковый словарь русского языка. М.: Азъ, 1994. С. 254.

11. Ровинский Е.А. Основные вопросы советского финансового права. М.: Госюриздат, 1960. С. 6, 7.

12. Сабо И. Основы теории права / Пер. с венг. М., 1974. С. 118.

13. Соколова Э.Д. Правовые основы финансовой системы России / Отв. ред. Е.Ю. Грачева. М.: ИД «Юриспруденция», 2006. С. 29.

14. Теория права и государства: Учебник / Под ред. проф. В.В. Лазарева. М., 1996. С. 342-343.

15. Финансовое право: Учебник / Отв. ред. Н.И. Химичева. 3-е изд., перераб. и доп. М.: Юристъ, 2003. С. 85.

16. Финансовое право: Учебник / Под ред. О.Н. Горбуновой. 2-е изд., перераб. и доп. М.: Юристъ, 2000. С. 16.

17. Химичева Н.И., Покачалова Е.В. Финансовое право / Отв. ред. докт. юрид. наук, проф. Н.И. Химичева. М.: Норма, 2005. С. 104.

18. Худяков А.И. Основы теории финансового права. М., 1995. С. 33.

19. Худяков А.И. Финансовое право Республики Казахстан. Общая часть. 2001. С. 16, 17.

20. Шагиева Р.В. Финансовая деятельность: сущность, содержание и формы осуществления // Вестник Владимирского юридического института ФСИН. 2012. № 2.

21. Вожова Е.М. Министерство финансов Российской Федерации как участник финансовых правоотношений // NB: Административное право и практика администрирования. - 2013. - 1. - С. 12-29. DOI: 10.7256/2306-9945.2013.1.434. URL: http://www.e-notabene.ru/al/article_434.html

22. Гуляихин В.Н. Структурно-функциональные особенности различных состояний правосознания человека // NB: Вопросы права и политики. - 2012. - 2. - C. 90-116. URL: http://www.e-notabene.ru/lr/ article_153.html

23. Полищук Д.А. Критериальная база оценки эффективности правоохранительной деятельности // NB: Российское полицейское право. - 2014. - 1. - С. 1-8. DOI: 10.7256/2306-4218.2014.1.9270. URL: http://www.e-notabene.ru/pm/article_9270.html

24. Гуляихин В.Н. Семья как субъект ранней правовой социализации // NB: Вопросы права и политики. - 2013. - 7. - C. 56-66. DOI: 10.7256/2305-9699.2013.7.9007. URL: http://www.e-notabene.ru/lr/ article_9007.html

25. Вожова Е.М. Министерство финансов Российской Федерации: обзор современного состояния субъекта финансового права // NB: Административное право и практика администрирования. - 2012. 1. - C. 1-16. URL: http://www.e-notabene.ru/al/article_433.html

26. Гуляихин В.Н. Правовая культура как объект научного исследования: методологические подходы, структура и критерии оценки // NB: Вопросы права и политики. - 2013. - 4. - С. 135-158. DOI: 10.7256/2305-9699.2013.4.635. URL: http://www.e-notabene.ru/lr/article_635.html

27. Гуляихин В.Н. Правовой менталитет российских граждан // NB: Вопросы права и политики. - 2012. 4. - C. 108-133. URL: http://www.e-notabene.ru/lr/article_310.html

28. Гуляихин B.Н. Психосоциальные формы правового нигилизма человека // NB: Вопросы права и политики. - 2012. - 3. - С. 108-148. URL: http://www.e-notabene.ru/lr/article_240.html

29. Гуляихин В.Н. Архетипы правосознания в системе правовой культуры личности // NB: Вопросы права и политики. - 2014. - 1. - C. 54-74. DOI: 10.7256/2305-9699.2014.1.10486. URL: http://www.enotabene.ru/lr/article_10486.html

30. А.С. Емельянов К вопросу о предмете административного и финансового права // Право и политика. 2012. - 12. - С. 2061-2067.

31. Колесников Ю.А. Финансово-правовое обеспечение передачи части государственных полномочий органам местного самоуправления // Административное и муниципальное право. - 2012. - 5. C. 18-21.

32. Моргун О.В., Щедрин Н.В. Основания и пределы мер финансовой безопасности // Актуальные проблемы российского права. - 2013. - 9. - С. 1165-1173.

33. Саркисов А.К. Финансово-правовое регулирование государственного кредита в Российской Федерации // Административное и муниципальное право. - 2010. - 1. - С. 68-78. 
34. Лагутин И.Б. Финансовый контроль как категория российского финансового права: новые подходы к определению // LEX RUSSICA (РУССКИЙ ЗАКОН). - 2009. - 3. - С. 593-604.

\section{References:}

1. Aktual'nye problemy teorii i praktiki gosudarstvennoi deyatel'nosti / Otv. red. prof. I.A. Galagan. Voronezh, 1990, S. 45.

2. Veremeenko I.I. K voprosu o predmete finansovogo prava. Aktual'nye voprosy administrativnogo i finansovogo prava: Sbornik nauchnykh trudov. Vyp. 2. M.: MGIMO(U) MID Rossii, 2004. S. 12.

3. Vitchenko A.M. Teoreticheskie problemy issledovaniya gosudarstvennoi vlasti. Saratov, 1982. S. 186.

4. Grudtsyna L.Yu. Grazhdanskoe obshchestvo i chastnoe pravo // Mezhdunarodnyi akademicheskii zhurnal Rossiiskoi akademii estestvennykh nauk. 2013. № 4. S. 69-79.

5. Karaseva M.V. Finansovoe pravo. Obshchaya chast': Uchebnik. M.: Yurist”, 1999. S. 14.

6. Karaseva M.V., Krokhina Yu.A. Finansovoe pravo / Pod red. dokt. yurid. nauk, prof. M.V. Karasevoi. M.: Izdatel'stvo «Norma» (Izdatel'skaya gruppa Norma-Infra), 2001. S. 9.

7. Krokhina Yu.A. Finansovoe pravo Rossii: Uchebnik. 3-e izd., pererab. i dop. M.: NORMA, 2008. S. 36.

8. Lerua Maksim. Evolyutsiya gosudarstvennoi vlasti (sindikaty chinovnikov) / Per. s fr. SPb., 1907. S. 47.

9. Loskutov A.E. Raspredelenie nalogovykh dokhodov mezhdu gosudarstvennymi i mestnymi byudzhetami: sravnitel'no-pravovoe issledovanie. Avtoreferat dis. ... kand. yurid. nauk. Saratov, 2006. S. 3.

10. Ozhegov S.I., Shvedova N.Yu. Tolkovyi slovar' russkogo yazyka. M.: Az", 1994. S. 254.

11. Rovinskii E.A. Osnovnye voprosy sovetskogo finansovogo prava. M.: Gosyurizdat, 1960. S. 6, 7.

12. Sabo I. Osnovy teorii prava / Per. s veng. M., 1974. S. 118.

13. Sokolova E.D. Pravovye osnovy finansovoi sistemy Rossii / Otv. red. E.Yu. Gracheva. M.: ID «Yurisprudentsiya», 2006. S. 29.

14. Teoriya prava i gosudarstva: Uchebnik / Pod red. prof. V.V. Lazareva. M., 1996. S. 342-343.

15. Finansovoe pravo: Uchebnik / Otv. red. N.I. Khimicheva. 3-e izd., pererab. i dop. M.: Yurist", 2003. S. 85.

16. Finansovoe pravo: Uchebnik / Pod red. O.N. Gorbunovoi. 2-e izd., pererab. i dop. M.: Yurist", 2000. S. 16.

17. Khimicheva N.I., Pokachalova E.V. Finansovoe pravo / Otv. red. dokt. yurid. nauk, prof. N.I. Khimicheva. M.: Norma, 2005. S. 104.

18. Khudyakov A.I. Osnovy teorii finansovogo prava. M., 1995. S. 33.

19. Khudyakov A.I. Finansovoe pravo Respubliki Kazakhstan. Obshchaya chast'. 2001. S. 16, 17.

20. Shagieva R.V. Finansovaya deyatel'nost': sushchnost', soderzhanie i formy osushchestvleniya // Vestnik Vladimirskogo yuridicheskogo instituta FSIN. 2012. № 2.

21. Vozhova E.M. Ministerstvo finansov Rossiiskoi Federatsii kak uchastnik finansovykh pravootnoshenii // NB: Administrativnoe pravo i praktika administrirovaniya. - 2013. - 1. - C. 12-29. DOI: 10.7256/23069945.2013.1.434. URL: http://www.e-notabene.ru/al/article_434.html

22. Gulyaikhin V.N. Strukturno-funktsional'nye osobennosti razlichnykh sostoyanii pravosoznaniya cheloveka // NB: Voprosy prava i politiki. - 2012. - 2. - C. 90-116. URL: http://www.e-notabene.ru/ lr/article_153.html

23. Polishchuk D.A. Kriterial'naya baza otsenki effektivnosti pravookhranitel'noi deyatel'nosti // NB: Rossiiskoe politseiskoe pravo. - 2014. - 1. - C. 1-8. DOI: 10.7256/2306-4218.2014.1.9270. URL: http://www.enotabene.ru/pm/article_9270.html

24. Gulyaikhin V.N. Sem'ya kak sub"ekt rannei pravovoi sotsializatsii // NB: Voprosy prava i politiki._2013. - 7.— C. 56-66. DOI: 10.7256/2305-9699.2013.7.9007. URL: http://www.e-notabene.ru/lr/article_9007.html

25. Vozhova E.M. Ministerstvo finansov Rossiiskoi Federatsii: obzor sovremennogo sostoyaniya sub"ekta finansovogo prava // NB: Administrativnoe pravo i praktika administrirovaniya. - 2012. - 1. - C. 1-16. URL: http://www.e-notabene.ru/al/article_433.html

26. Gulyaikhin V.N. Pravovaya kul'tura kak ob"ekt nauchnogo issledovaniya: metodologicheskie podkhody, struktura i kriterii otsenki // NB: Voprosy prava i politiki. - 2013. - 4. - C. 135-158. DOI: 10.7256/23059699.2013.4.635. URL: http://www.e-notabene.ru/lr/article_635.html

27. Gulyaikhin V.N. Pravovoi mentalitet rossiiskikh grazhdan // NB: Voprosy prava i politiki. - 2012. - 4. C. 108-133. URL: http://www.e-notabene.ru/lr/article_310.html 
28. Gulyaikhin V.N. Psikhosotsial'nye formy pravovogo nigilizma cheloveka // NB: Voprosy prava i politiki. 2012. - 3. - C. 108-148. URL: http://www.e-notabene.ru/lr/article_240.html

29. Gulyaikhin V.N. Arkhetipy pravosoznaniya v sisteme pravovoi kul'tury lichnosti // NB: Voprosy prava i politiki. — 2014. - 1. — C. 54-74. DOI: 10.7256/2305-9699.2014.1.10486. URL: http://www.e-notabene. $\mathrm{ru} / \mathrm{lr} /$ article_10486.html

30. A.S. Emel'yanov K voprosu o predmete administrativnogo i finansovogo prava // Pravo i politika. — 2012. 12. - C. 2061-2067.

31. Kolesnikov Yu.A. Finansovo-pravovoe obespechenie peredachi chasti gosudarstvennykh polnomochii organam mestnogo samoupravleniya // Administrativnoe i munitsipal'noe pravo. - 2012. - 5. - C. 18-21.

32. Morgun O.V., Shchedrin N.V. Osnovaniya i predely mer finansovoi bezopasnosti // Aktual'nye problemy rossiiskogo prava. - 2013. - 9. - C. 1165-1173.

33. Sarkisov A.K. Finansovo-pravovoe regulirovanie gosudarstvennogo kredita v Rossiiskoi Federatsii // Administrativnoe i munitsipal'noe pravo. - 2010. - 1. - C. 68-78.

34. Lagutin I.B. Finansovyi kontrol' kak kategoriya rossiiskogo finansovogo prava: novye podkhody k opredeleniyu // LEX RUSSICA (RUSSKII ZAKON). — 2009. - 3. - C. 593-604. 